\title{
Encheliophis chardewalli: A New Species of Carapidae (Ophidiiformes) from French Polynesia, with a Redescription of Encheliophis vermicularis
}

\author{
ERic PARMentier
}

\begin{abstract}
A specimen of Encheliophis was found in the coelomic cavity of a sea cucumber in Moorea (French Polynesia). The skeletal morphology (skull, girdles, vertebrae) reveal it to be a new species, described herein as Encheliophis chardewalli. It is separable from all described species of Encheliophis (except Encheliophis vermicularis) by the lack of pectoral fins and from $E$. vermicularis by the larger and fewer teeth on the lower jaw (14 vs more than 20 in $E$. vermicularis) and by seven branchiostegal rays (vs six in E. vermicularis).
\end{abstract}

$\mathrm{T}^{\mathrm{H}}$ HE family Carapidae contains an ecologically diverse group of marine fish that are most abundant and diverse in tropical seas (Williams, 1984; Parmentier and Vandewalle, 2003). Several species belonging to the genera Onuxodon, Carapus, and Encheliophis are well known for their unusual behavior of entering and living inside invertebrate hosts such as sea cucumbers, sea stars, or bivalves (Trott, 1981). Species belonging to the genera Onuxodon and Carapus are commensal and species of the genus Encheliophis are parasites (Parmentier et al. 2000). As determined by Parmentier et al. (2000), the genus Encheliophis Müller, 1842, contains four species: Encheliophis gracilis (Bleeker, 1856), Encheliophis sagamianus (Tanaka, 1908), Encheliophis vermiops Markle and Olney, 1990, and Encheliophis vermicularis Müller, 1842. This genus is diagnosed by 11 synapomorphies (Parmentier et al., 2000), among which is an important field character: the maxillaries and premaxillaries united by short connective fibres to function as a unit, and both elements bound to the skin preventing large mouth openings (Parmentier et al., 1998).

Encheliophis vermicularis is distinctive among previously known carapids in that it lacks an externally visible pectoral fin (Müller, 1842; Markle and Olney, 1990; Nielsen et al., 1999). This pearlfish, originally described from the Philippines, has been found in several species of sea cucumbers: in Holothuria leucospilota by Masuda et al. (1984), in Holothuria scabra by Murdy and Cowan (1980), in Holothuria lubrica by Steinbeck and Ricketts (1941), and in Thelenota ananas by Markle and Olney (1990). Records indicate that it occurs between $30 \mathrm{~N}$ and $30 \mathrm{~S}$ latitudes within the Indo-Pacific region, from the Red Sea to the Gulf of California (Markle and Olney, 1990). This species has two junior synonyms: Encheliophis hancocki (Reid, 1940) and Encheliophis jordani Heller and Snodgrass, 1903.

A specimen of Encheliophis, first attributed to
E. vermicularis because of the lack of pectoral fins, was caught in Opanohu Bay (Moorea, French Polynesia). However, staining revealed several features that distinguish it from $E$. vermicularis, the latter of which is redescribed to include osteological features not previously recorded.

\section{Materials AND Methods}

The present specimen was compared to two specimens of $E$. vermicularis from New Caledonia (VIMS 09600, 123-148 mm SL), radiographs of the neotype of E. vermicularis (USNM 298307, $130 \mathrm{~mm}$ SL), holotypes of E. jordani (CAS 6345, $114 \mathrm{~mm}$ SL), and E. hancocki (USNM 101789, $74.8 \mathrm{~mm}$ SL and USNM $10179050 \mathrm{~mm} \mathrm{SL}$; caudal tip is missing).

The specimen from Moorea and the two VIMS specimens were alizarin stained (Taylor and Van Dyke, 1985). The fish were examined with a Wild M10 binocular microscope coupled with a camera lucida. Measurements were made to the nearest $0.1 \mathrm{~mm}$. The cephalic morphology of the genus Encheliophis has been thoroughly described by Markle and Olney (1990), and Parmentier et al. (1998, 2000). The soundproducing apparatus is described in detail in Parmentier et al. (2003).

\section{Encheliophis chardewalli, n. sp}

Figures 1-2, 3A, 4A, 5A

Holotype-USNM 372738, $72 \mathrm{~mm}$ SL, collected on the west side of bay mouth of Opanohu Bay, Moorea, French Polynesia; E. Parmentier, 15 July 2002. It was found in the coelomic cavity of the holothuroid Actinopyga mauritania caught at a depth of $1 \mathrm{~m}$ in the lagoon at a distance of 15 $m$ from the beach.

Diagnosis. - In the field, separable from all described species of Encheliophis (except E. vermi- 


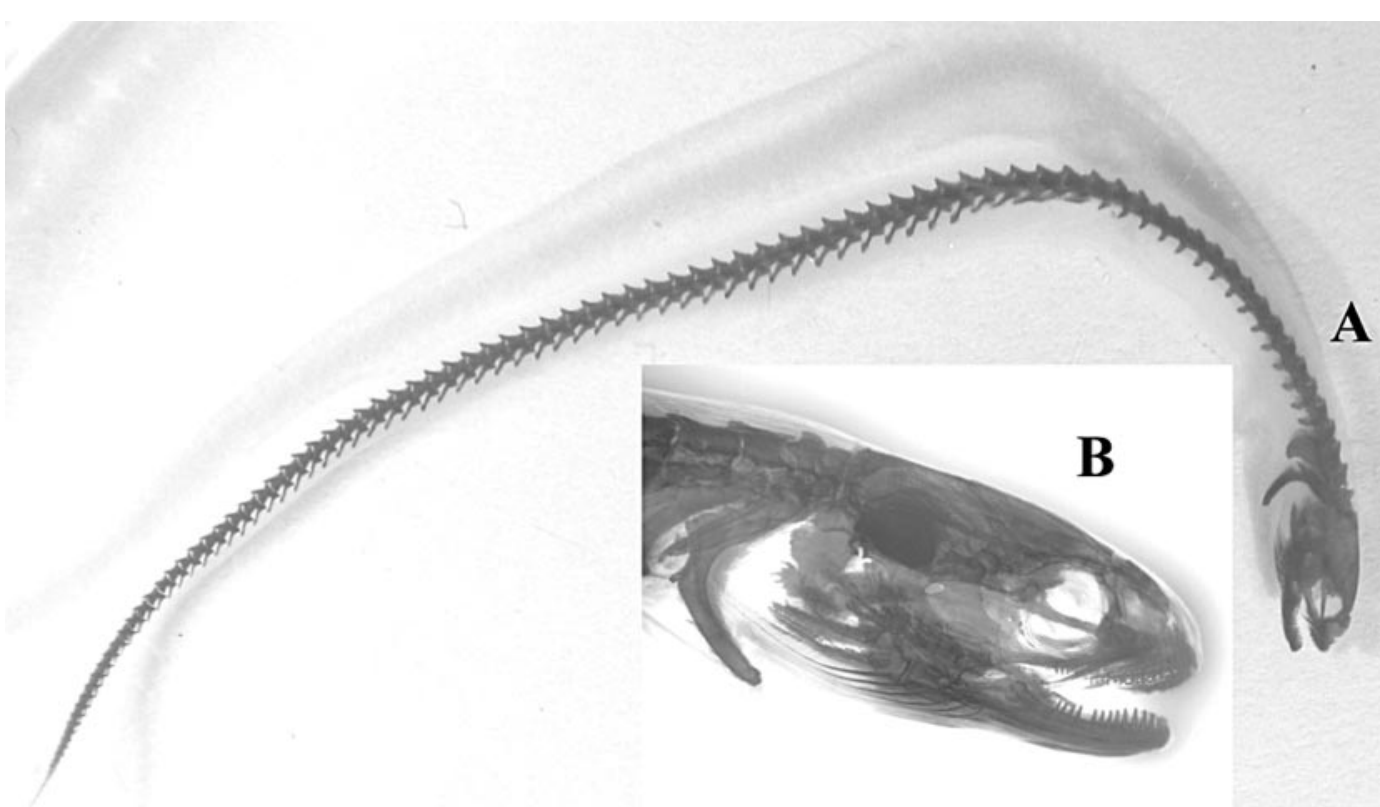

Fig. 1. Encheliophis chardewalli cleared-and-stained holotype (A), USNM 372738, 72 mm SL and (B) enlarged view of the head (head length $5.2 \mathrm{~mm}$ ).

cularis) by the lack of pectoral fins. Separable from $E$. vermicularis by fewer, larger teeth on the dentary (14 vs more than 20 in E. vermicularis; Fig. 3) and by seven branchiostegal rays (vs six in E. vermicularis). See "Comparison" for further characters not observable in the field.

Description.-The head measures (from the anterior part of the premaxilla to the posterior part of the opercle) $5.2 \mathrm{~mm}$. The horizontal diameter of the eye represents $24 \%$ of the head length, depth at the posterior end of the lower jaw is $51 \%$ of the head length and body depth at the level of the pectoral girdle is $63 \%$ of the head length.

The maxilla is toothless. Outer cardiform teeth are present at the anterior end of the premaxilla and small conical teeth are organized in

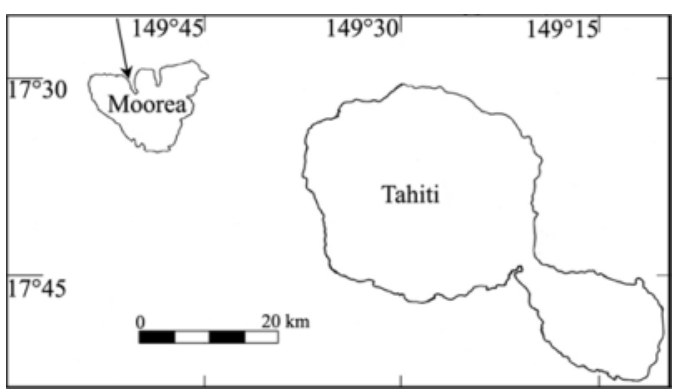

Fig. 2. Type locality of Encheliophis chardewalli in Moorea (French Polynesia) marked by arrow. one row on the anterior part of the premaxilla, behind the cardiform teeth. The premaxilla and adnate maxilla are characterized by their small size and do not reach the coronoid process of the dentary. The latter and the articuloangular coronoid process have the same height. The 14 teeth of the lower jaw are curved and arranged in a single row. They are longer and larger than those of the upper jaw. Small conical teeth are arranged in two forward rows and in a single posterior row on the palatines. The vomer has a group of seven conical teeth.

Mesethmoid is large. Lateral ethmoid is Ushaped and has three shelves (Fig. 3A). Two (LETHc and LETHb) are in contact with the frontal whereas the third (LETHa) projects laterally. The quadrate is anterior to a vertical line passing through the anterior articulation of the hyomandibular on the neurocranium. The operculum forms a rounded plate. The hyoid arch bears seven branchiostegal rays. The metapterygoid is reduced and overlaps only the hyomandibular.

The body lacks pelvic, caudal, and externally visible pectoral fins. Anal fin originates behind opercle. It is longer than dorsal fin, both fins meeting at posterior tip of body. Pectoral girdle composed of three bones: postemporal, supracleithrum and cleithrum. Cleithrum characterised by large expansion of its dorsal part. Pectoral fin not externally visible and made of two small bones (Fig. 4A). The coracoid possesses 

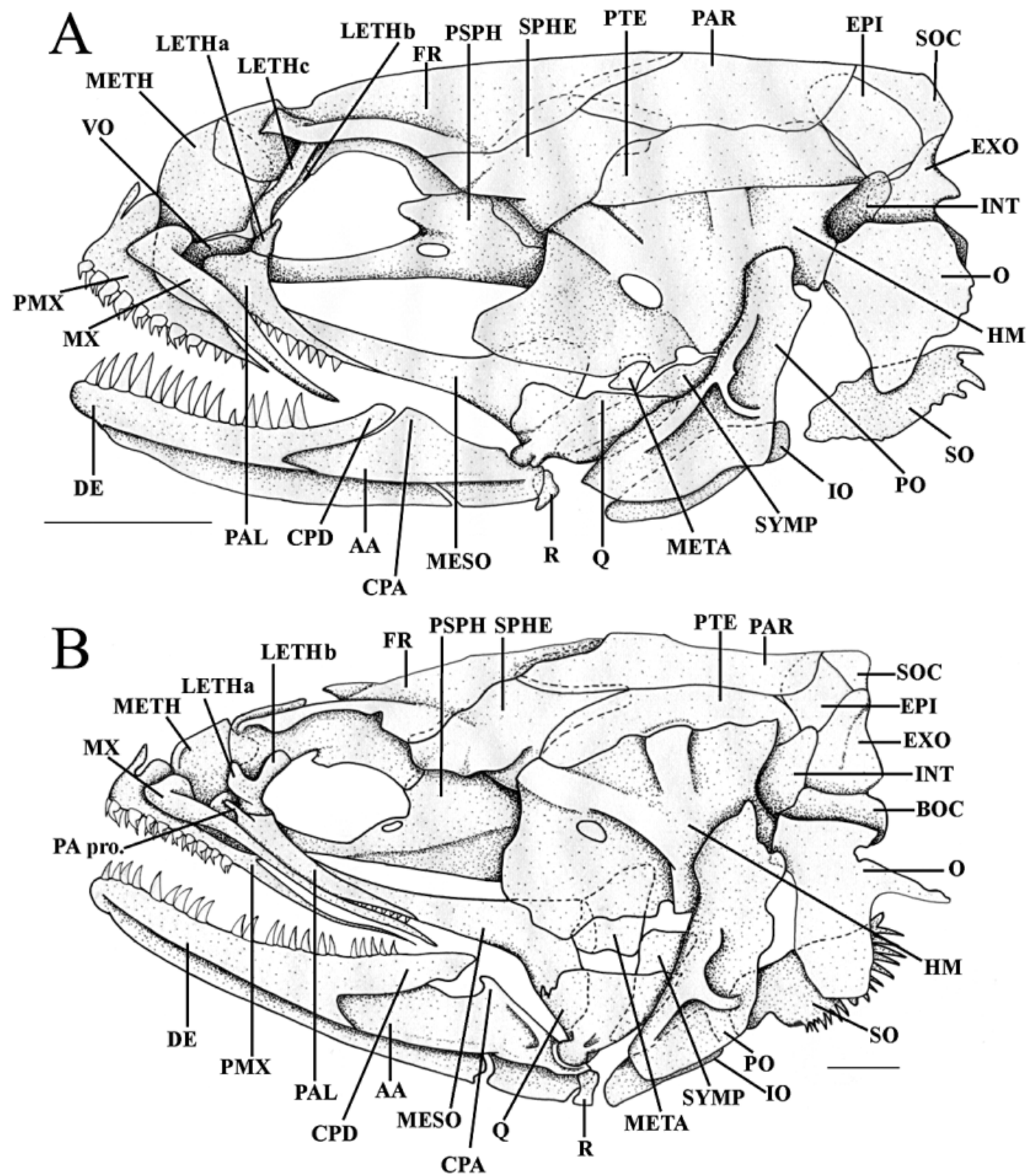

Fig. 3. Lateral view of the skull, scale bars equal $1 \mathrm{~mm}$. (A) Encheliophis chardewalli, USNM 372738, $72 \mathrm{~mm}$ SL, Opanohu Bay, Moorea, French Polynesia; (B) Encheliophis vermicularis, VIMS 09600, 123 mm SL, Maitre Islet, New Caledonia. AA, articulo-angular; BOC, basioccipital; CPA, coronoid process of the articulo-angular; CPD, coronoid process of the dentary; DE, dentary; EPI, epiotic; EXO, exoccipital; FR, frontal; HM, hyomandibular; INT, intercalar; IO, interopercle; LETH, lateral ethmoid and number of the branch; MESO, mesopterygoid; META, metapterygoid; METH, mesethmoid; MX, maxilla; O, opercle; PAL, palatine; PA pro., palatine process; PAR, parietal; PSPH, parasphenoid; PMX, premaxilla; PO, preopercle; PTE, pterotic; PTT, posttemporal; Q quadrate; R, retroarticular; SO, subopercle; SOC, supraoccipital; SPHE, sphenotic; SYMP, symplectic; VO, vomer.

an elongated cartilaginous ventral process and is surmounted by the small scapula.

There are 107 vertebrae, of which there are 20 precaudal vertebrae. Two first vertebrae each bear a rodlike epineural. Third vertebra with an elongated and enlarged swim bladder plate (Parmentier et al., 2003) that covers the anterior part of swim bladder and reaches the fifth 


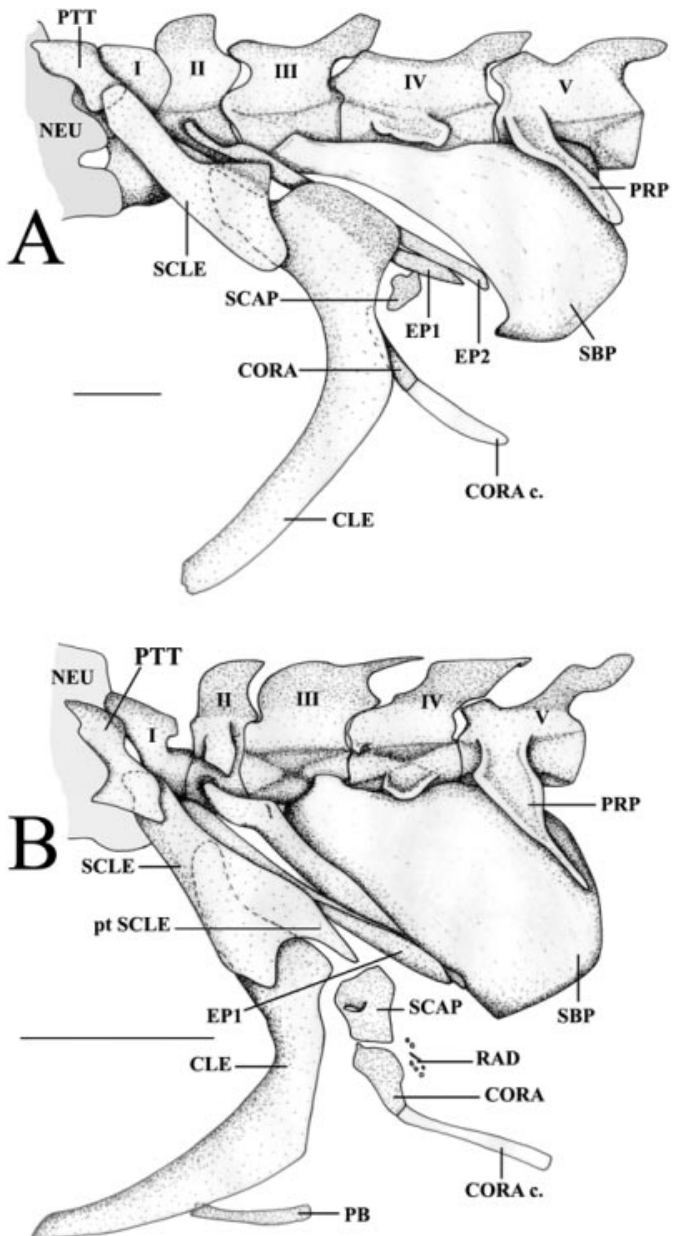

Fig. 4. Lateral view of the anterior part of the vertebral column and neurocranium, scale bars equal 0.5 mm. (A) Encheliophis chardewalli, USNM 372738, 72 mm SL, Opanohu Bay, Moorea, French Polynesia; (B) Encheliophis vermicularis, VIMS 09600, 123 mm SL, Maitre Islet, New Caledonia. CLE, cleithrum; CORA, coracoid; CORA c., coracoid cartilage; EP\#, epineural\#; NEU, neurocranium; PB, pelvic bone; PRP, parapophysis; PTT, posttemporal; pt SCLE, posterior tip of the SCLE; RAD, radials; SBP, swim bladder plate; SCAP, scapula; SCLE, supracleithrum; I-V, vertebral number.

vertebra. Fourth epineural highly reduced and overlies swim bladder plate. From the fifth vertebra, all other precaudal vertebrae bear on each side a short parapophysis (Fig. 5A). The neural spines of these vertebra are short and nearly horizontal.

The body is dark blue with melanophores concentrated at the posterior end of the body and of the anal and dorsal fin. A translucent area is present behind the opercle and marks the anterior end of the swim bladder. Melano-

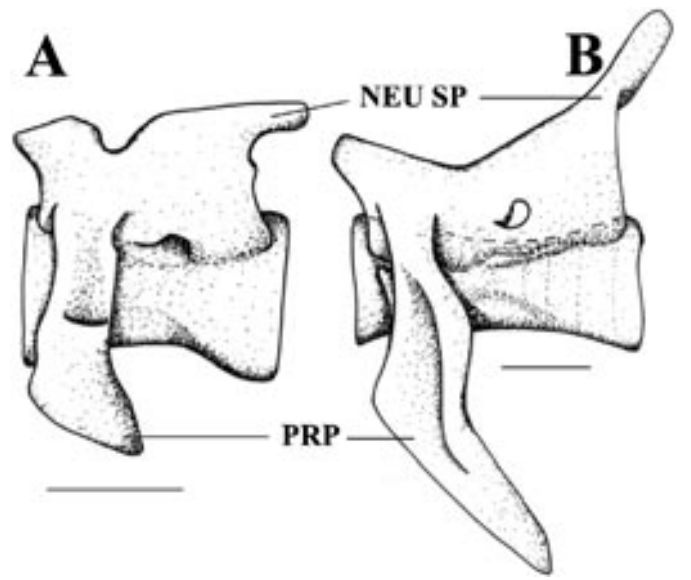

Fig. 5. Lateral view of the 10th precaudal vertebra, scale bars equal $0.5 \mathrm{~mm}$. (A) Encheliophis chardewalli, USNM 372738, 72 mm SL, Opanohu Bay, Moorea, French Polynesia; (B) Encheliophis vermicularis, VIMS 09600, 123 mm SL, Maitre Islet, New Caledonia. NEU SP, neural spine; PRP, parapophysis.

phores are present on the brain but are absent from the jaws and opercle. From a dorsal view, it is possible to discern the sagittae.

Etymology.-Encheliophis chardewalli is the combination of the names of Dr. Chardon M. and Dr. Vandewalle $\mathrm{P}$. of the University of Liège (Belgium). It is in recognition of their scientific accomplishments in ichthyology.

Redescription of Encheliophis vermicularis Müller 1842.-Encheliophis vermicularis is described in Müller (1842), Trott (1970), Murdy and Cowan (1980), Markle and Olney (1990). However, these descriptions principally concern morphometric and meristic data. The features that appear in this study have not been described previously and are used for the comparison with $E$. chardewalli.

Outer cardiform teeth and an inner row of small conical teeth are present on the anterior end of the premaxilla. The premaxilla and the adnate maxilla reach the posterior end of the eye (Fig. 3B). Its dentary bears 22-23 conical teeth in a single row but some smaller teeth on two rows posteriorly, on the coronoid process. The latter is higher than the articulo-angular coronoid process.

Small mesethmoid. Lateral ethmoid Ushaped and composed of two shelves, the first (LETHa) projects laterally and the second is in contact with the frontal (LETHb). Quadratemandible articulation behind a vertical line passing through the anterior articulation of the 
hyomandibular on the neurocranium. Operculum V-shaped with its lower part enlarged. The hyoid arch has six branchiostegal rays. Metapterygoid enlarged and overlapping the mesopterygoid and the hyomandibular.

The supracleithrum possesses a caudo-ventrally oriented posterior tip (Fig. 4B; see also Williams 1984) and covers a great part of the cleithrum. Pectoral fin composed of large bones and small proximal radials are visible (Fig. 4B).

The vertebral columns of the two VIMS specimens have 123 and 117 vertebrae, respectively. First two vertebrae each bear a rodlike epineural rib. Third vertebra has an elongated and enlarged swim bladder plate that covers the anterior end of the swim bladder and reaches the fifth vertebra (Fig. 4B). From the fifth vertebra on, all other precaudal vertebrae bear on each side a parapophysis longer than the vertebral body. Their neural spines appear more vertically than horizontally oriented. Between the right and left cleithra, two small rodlike bones correspond to reduced pelvic bones.

At the level of the lateral line, these specimens have on each side a small scale per vertebra until the 70th vertebra.

Comparison.-Encheliophis chardewalli is distinguished from E. vermicularis by at least 14 characters: (1) the premaxilla and the maxilla are proportionately shorter; (2) the lateral ethmoid possesses three shelves (vs two); (3) teeth of the dentary are proportionally larger and fewer (14 vs more than 20); (4) the opercular bone is rounded (vs V-shaped); (5) the hyoid arch bears seven branchiostegal rays (vs 6); (6) the supracleithrum does not have an elongate posterior tip; (7) the neural spine of the first vertebra is larger and rounded; (8) lack of pelvic bones; (9) lack of scales; (10) pectoral bones (scapula and coracoid) reduced; (11) neural arches and parapophysis reduced; (12) larger mesethmoid; (13) reduced metapterygoid and (14) shorter coronoid process of the dentary.

\section{Discussion}

The dentition of the thin premaxilla (outer cardiform teeth and an inner row of small conical teeth), and the presence of the adnate maxilla, which is bound by skin to the head, show that this specimen belongs to Encheliophis following the diagnosis proposed by Parmentier et al. (2000). Encheliophis chardewalli could be a paedomorphic form given that its skeletal morphology has a series of features that seem to exhibit arrested development. (1) Studies of development in five carapids genera show a trend to an increasingly posterior placement of the quadrate-dentary articulation (unpubl. data). In E. chardewalli, the more forward position of the quadrate-dentary articulation and the more leaning operculum could be the result of arrested development. (2) Arrested development might also explain the more regular form of the opercle in E. chardewalli, which is otherwise Vshaped in all other Carapidae (Parmentier et al., 2000), even in the Carapini tribe (Carapus and Encheliophis) larvae (Parmentier et al., 2002). (3) The pectoral fin is less developed and the pelvic bones are missing in E. chardewalli. (4) The upper jaws appear to be less developed than in all other Carapidae (Markle and Olney, 1990; Parmentier et al., 2000).

However, other characters show that the specimen described in this study can not be the larval or juvenile form of E. vermicularis. For example, all bones of the neurocranium and suspensorium found in other adult carapids are present in E. chardewalli, and are well ossified and characterized by major overlaps (Parmentier et al., 2002). The lateral ethmoid has three shelves in E. chardewalli; a feature shared by all the Carapini except E. vermicularis and E. gracilis. Encheliophis chardewalli also shows better-developed conical teeth on the dentary.

\section{ACKNOWLEDGMENTS}

I thank J. Million, Y. Chancerelle, and J. Algret (CRIOBE) for helping to obtain carapids in Moorea. I am grateful to S. Jewett and S. Raredon (USNM), to D. Catania (CAS) for giving X-ray photographs, and to J. E Olney (VIMS) for giving E. vermicularis specimens. J. T. Williams (USNM) kindly commented on an earlier version of this text. All collecting and handling of specimens was in accordance with policies and recommendations of University of Liege. This work was supported by grant 2.4560 .96 from the Fonds National de la Recherche Scientifique of Belgium.

\section{Literature Cited}

Markle, D. F., And J. E. Olney. 1990. Systematics of the Pearlfish (Pisces: Carapidae). Bull. Mar. Sci. 47: 269-410.

Masuda, H., K. Amaoka, C. Araga, T. Uyeno, and T. Yoshino. 1984. The fishes of the Japanese Archipelago. Tokai Univ. Press, Tokyo, Japan.

MülleR, J. 1842. Beobachtungen über die schwimmblase der Fische, mit bezug auf einige neue fischgattungen. Arch. Anat. (Müller) Jahr 1842:307-329.

Murdy, E. O., AND M. E. Cowan. 1980. Observation on the behaviour and symbiotic relationship of the 
pearlfish Encheliophis vermicularis (Osteichthys: Carapidae). Kalikasan Philippine J. Biol. 9:309-312.

Nielsen, J. G., D. M. Cohen, D. F. Markle, And C. R. RoBINs. 1999. FAO species catalogue. Vol. 18. Ophidiiform fishes of the world (order Ophidiiformes). An annotated and illustrated catalogue of pearlfishes, cusk-eels, brotulas and other ophidiiform fishes known to date. FAO Fish. Synop. 125:1-178.

Parmentier, E., And P. Vandewalle. 2003. Morphological adaptations of Pearlfish (Carapidae) to their various habitats, p. 261-276. In: Fish adaptations. A. L. Val and B. G. Kapoor (eds.). Oxford.

, M. Chardon, M. Poulicek, J. C. Bussers, ANd P. VANDEWALLE. 1998. Morphology of the buccal apparatus and related structures in four Carapidae. Aust. J. Zool. 46:391-404.

G. Castillo, M. Chardon, and P. VandewalLE. 2000. Phylogenetic analysis of the pearlfish tribe Carapini (Pisces: Carapidae). Acta Zool. 81:293306.

, A. Lo-Yat, and P. Vandewalle. 2002. Identification of four French Polynesia tenuis Carapini (Carapidae: Teleostei). Mar. Biol. 140:633-638.

P. VAndewalle, and J.P. Lagardère. 2003. Sound producing mechanisms and recordings in
Carapini species (Teleostei, Pisces). J. Comp. Physiol. A 189:283-292.

SteinbeCK, J., AND E. F. RicketTs. 1941. Sea of Cortez. Viking Press, New York.

Taylor, W. R., and G. C. Van Dyke. 1985. Revised procedure for staining and clearing small fishes and other vertebrates for bone and cartilage study. Cybium 2:107-119.

Trotт, L. B. 1970. Contribution of the biology of carapid fishes (Paracanthopterygian: Gadiformes). Univ. Calif. Publ. Zool. 89:1-41.

- 1981. A general review of the pearlfishes (Pisces, Carapidae). Bull. Mar. Sci. 31:623-629.

Williams, J. T. 1984. Synopsis and phylogenetic analysis of the pearlfish subfamily Carapinae (Pisces: Carapidae). Bull. Mar. Sci. 34:386-397.

Laboratoire de Morphologie Fonctionnelle ET Evolutive (LMFE), BAT. B6, University of Liège, Belgium; ANd Centre de RecherCHE INSUlaire ET OBSERVATOIRE DE L'EnVIronnement, C.R.I.O.B.E/E.P.H.E., B.P. 1013, MOOREA French POlynesia. E-mail: e.parmentier@ulp.ac.be. Submitted: 9 April 2003. Accepted: 16 Aug. 2003. Section editor: D. G. Buth. 